\title{
Initial Evidence of Religious Practice and Belief in Depressed African American Cancer Patients
}

\author{
Amy Y. Zhang ${ }^{*}, 1$, Faye Gary ${ }^{1}$ and Hui $\mathrm{Zhu}^{2}$ \\ ${ }^{I}$ Frances Payne Bolton School of Nursing, Case Western Reserve University, 10900 Euclid Avenue, Cleveland, OH \\ 44106-4904, USA \\ ${ }^{2}$ School of Medicine, Case Western Reserve University, 10900 Euclid Avenue, Cleveland, OH 44106-4904, USA
}

\begin{abstract}
Objective: This study examined spiritual coping (beliefs and practices) of depressed African American cancer patients through a comparison with depressed White cancer patients and non-depressed African American cancer patients.

Methods: Using mixed methods, 74 breast $(n=41)$ and prostate $(n=33)$ cancer survivors including 34 depressed and 23 nondepressed African Americans and 17 depressed Whites were interviewed. The interviews were audiotaped and transcribed. Qualitative data analysis identified themes that were coded. The codes were entered into SPSS software. The Fisher's exact test was performed to examine group differences in self-reported spiritual coping.

Results: Significantly more depressed African Americans questioned God when learning of a cancer diagnosis than the non-depressed African Americans $(p=.03)$, but they did not differ from the depressed Whites in this regard $(p=.70)$. Significantly more depressed African Americans reported having faith in God $(p=.04)$, reading the bible $(p=.02)$, and conversing with God $(p=.01)$ than did the depressed Whites. They also reported praying alone $(p=.01)$ more frequently than the depressed Whites who, on the other hand, reported praying with others (non-family members) together for one's own health more frequently $(p=.04)$.

Conclusions: Depression is associated with a deepening need for spirituality and it affects religious beliefs and practices more in African American than White cancer patients. Given its important role in the lives of African American cancer patients, spirituality may be utilized as a reasonable, culturally-based approach to better assess and treat depression in these patients.
\end{abstract}

Keywords: African American, cancer, depression, race, pray, religion, spirituality.

\section{INTRODUCTION}

Many African Americans are highly spiritual and more likely resort to spirituality for healing than people from other ethnic groups [1]. Spirituality has been defined as an "inner path enabling a person to discover the essence of his/her being or the deepest values and meanings by which people live" [2]. Spiritual experiences may include a connection with a supernatural power or a higher being that is inspirational and can yield transcendent, renewed self. When facing a cancer diagnosis, African Americans are found to rely on their spirituality for coping [3, 4]. For example, it was reported that African Americans with breast cancer considered God as the main source of support as compared to White women with breast cancer who considered family as the main source of support [5]. The tendency of spiritual coping among African Americans has been associated with a long history of strong religious faith in God that sustained their endurance of hardships. A shared belief in God, as the divine master, is a distinct cultural value [6].

*Address correspondence to this author at the Frances Payne Bolton School of Nursing, Case Western Reserve University, 10900 Euclid Avenue, Cleveland, OH 44106-4904, USA; Tel: (216) 368-0968;

Fax: (216) 368-3542; E-mail: axz16@case.edu
Existing studies have primarily focused on describing African American's religious beliefs and its meanings in their daily lives [7, 8]. Levine et al. [9] studied 175 breast cancer patients including 67 African Americans. They identified several domains of a spiritual healing process including God as a comforting presence, doubt or questions about God, spiritual transformation of the self, and deepened faith and personal growth. These domains, emerging from patients' own narratives, portrayed a journey of spiritual healing after an initial cancer diagnosis. Despite increasing knowledge of the historical backgrounds and the meanings of spirituality for African American cancer patients, our understanding of how spirituality and mental well-being interface, particularly among the distressed African American cancer patients, remains largely unexplored. Gibson and Parker [10] studied the association between spirituality and psychological well-being among African Americans but did not find a direct significant relationship. It was acknowledged that faith in God is conducive to overcoming fatalism among African American cancer patients [11] and, yet, empirical evidence is limited.

Because spirituality potentially has an uplifting effect and health benefits [12], it is important to examine how it plays a role in African American cancer patients who are depressed. Studies in this area will provide insight into a better way of 
assisting African Americans with coping and healing. They are important particularly because African American cancer patients have higher mortality rates than their White counterparts [13]. Thus, in this study, we present some preliminary findings concerning African American cancer survivors who suffered from depression. We compared these patients with non-depressed African American and depressed White cancer patients on their recall of spiritual experiences to shed light on the issue of spiritual coping.

\section{MATERIALS AND METHODOLOGY}

The study used the mixed methods design to add breadth or depth to data analysis and findings by collecting qualitative and quantitative data. In this report, we applied the sequential mixed analysis, specifically, the sequential quantitative-qualitative analysis, to use quantitative findings to classify subjects into groups and then apply qualitative analysis to determine why the groups are different [14]. We then converted qualitative codes that resulted from the qualitative analysis to a quantitative form for data analysis.

This study was carried out in Cleveland, Ohio between 2006 and 2008. It was approved by the hospital Institutional Review Board (IRB) and monitored by a data and safety monitoring committee.

The hospital tumor registry was used to identify potentially eligible patients. Subject eligibility included a diagnosis of early-stage breast or prostate cancer (stages IIII) within the past three years and the completion of all cancer treatments for at least six months prior to the beginning of this research. Individuals with documented psychotic disorders were excluded. Patients with an existing diagnosis of depression or who had been prescribed antidepressant medications were eligible to participate in the study. With physicians' permission, an introductory letter from the principal investigator along with the IRB-approved consent form and the Center for Epidemiologic StudiesDepression Scale (CES-D) were mailed to the identified cancer patients. Trained research staff telephoned the patients to introduce the study and conduct an initial screening. The CES-D was used during the telephone screening to assess the patient's depression status. Demographic and medical treatment variables were collected at this time and verified with medical records. Eligible and consenting patients were recruited consecutively, yielding 75 subjects that consisted of 57 African Americans and 18 Whites.

The recruited study participants were interviewed in person at their homes or at other private safe locations. Three interviewers (two African Americans and one White) conducted the interview individually; each completed a 4hour training session in advance. The interviewers had a license in psychiatric nursing or social work and decadeslong clinical experience with individuals with mental illnesses. The literature indicates that ethnic match between the patient and the therapist enhances subject retention and utilization of services, possibly due to rapport [15]. Hence the interviewers were matched with study participants on racial/ethnic status to ensure cultural sensitivity during the interview and data collection process.

Written consent was obtained at the beginning of each interview. Thereafter, study participants were administered the Hamilton Rating Scale for Depression (HRSD) and Beck Depression Inventory-II (BDI-II) for evaluating the depression status. The interviewer's observational rating (not depressed, mildly depressed, moderately depressed or severely depressed) was also recorded. The interviewers then conducted an open-ended interview using an interview guide that included these questions: "Looking back at what you have been through since cancer diagnosis, have there been times and events at which you felt depressed? Can we talk about your experiences with these depressing times and events?" The interviewers probed subjects with further questions: "do you pray when you are feeling depressed?" "Can you talk about how you talk with God about your situation?" Participants' responses to this portion of the interview were analyzed and reported in this study. Interviews were audiotaped. Study investigators (authors) listened to $40 \%$ of the taped interviews to safeguard against interview deviation. Subjects received a $\$ 30$ honorarium for completing the interviews.

To ensure cultural awareness, an experienced African American transcriptionist transcribed all audiotapes. Two experienced coders (one White, one African American) developed a codebook based on five initial transcripts and then coded each transcript independently using Atlas.ti 5.2 software [16]. The researchers met biweekly to discuss emerging codes and to check coding consistency. The two sets of codes were merged into a single coding file to allow for exhaustive groupings of transcripts by themes. The principal investigator and an independent coder read the transcripts in each code, checked coding against original transcripts and finalized the codes. The codes were converted to an SPSS (IBM SPSS Statistics Version 20) database as a nominal variable, with " 1 " indicating the presence and " 0 " indicating the absence of a code in each transcript. The Fisher's exact test was performed to compare the depressed African American group with the other two study groups (the nondepressed African American and the depressed White cancer patients) on the frequency (occurrence) of each code, in order to identify group differences by race and depression status.

\section{RESULTS}

Demographics of the study sample are presented in Table 1. Subjects that exceeded a cutoff score on both of the Center for Epidemiological Studies Depression Scale (CES-D $\geq 16$ ) and another scale (the Hamilton Rating Scale for Depression $\geq 8$, the Beck Depression Inventory-II $\geq 14$, or an observer's rating) were identified as "depressed" to ensure accuracy of the depression assessment. This process resulted in 34 depressed and 23 non-depressed African American and 17 depressed White cancer patients in the study.

As Table 1 shows, the nondepressed African American group was older than the other two groups with a mean age of 67 (s.d. $=10, p \leq .05$ ). The three groups did not differ significantly in terms of gender, marital status, education, employment, income, and the type of treatment (surgery, radiation, and chemotherapy), despite the presence of some cross-group variations. There was not a significant difference between the depressed African American and depressed White groups on the severity level of depression with regard to any of the depression measures employed in this study. 
Table 1. Sample Demographics

\begin{tabular}{|c|c|c|c|c|c|c|}
\hline Variable & \multicolumn{2}{|c|}{ Not Depressed African American } & \multicolumn{2}{|c|}{ Depressed African American } & \multicolumn{2}{|c|}{ Depressed White } \\
\hline \multicolumn{7}{|l|}{ Gender } \\
\hline Male & 12 & $52 \%$ & 16 & $47 \%$ & 5 & $29 \%$ \\
\hline \multicolumn{7}{|l|}{ Marital status } \\
\hline Married & 12 & $52 \%$ & 10 & $29 \%$ & 10 & $59 \%$ \\
\hline Single & 4 & 17 & 10 & 29 & 3 & 18 \\
\hline Other (divorced etc.) & 7 & 30 & 14 & 41 & 4 & 24 \\
\hline$\geq$ College & 4 & 17 & 4 & 12 & 8 & 47 \\
\hline \multicolumn{7}{|l|}{ Employment } \\
\hline Full time & 6 & $26 \%$ & 8 & $25 \%$ & 9 & $53 \%$ \\
\hline Half time & 2 & 9 & 4 & 13 & 2 & 12 \\
\hline Unemployed & 15 & 65 & 20 & 63 & 6 & 35 \\
\hline \multicolumn{7}{|l|}{ Income (Optional) } \\
\hline$<\$ 15000$ (household) & 7 & $30 \%$ & 10 & $29 \%$ & 1 & $6 \%$ \\
\hline$<\$ 25000$ & 4 & 17 & 4 & 12 & 0 & 0 \\
\hline Had Chemotherapy & 6 & $26 \%$ & 11 & $32 \%$ & 7 & $41 \%$ \\
\hline \multicolumn{7}{|c|}{ Level of Depression (Observer Rating) } \\
\hline Mild to moderate & & & 13 & $38 \%$ & 9 & $53 \%$ \\
\hline Severe & & & 21 & 62 & 8 & 47 \\
\hline
\end{tabular}

The qualitative data analysis revealed 14 themes that emerged from subject interview narratives and clustered into four main areas as shown on Table 2: religious belief (e.g., believing in God's plan and healing power); religious practice since a cancer diagnosis (e.g., prayer, going to church); religious background (e.g., religious upbringings); and appraisal of faith (e.g., how faith helped recovery). Significant group differences were observed in the areas of religious beliefs and practices. When discussing religious beliefs, significantly more depressed African Americans reported having faith in God than the depressed Whites $(p=.04)$, but there was not a significant difference between the depressed and nondepressed African Americans. Further, significantly more depressed than non-depressed African Americans asked God "why me?" at learning the cancer diagnosis $(p=.03)$ without significantly differing from the depressed Whites. When discussing religious practice, more depressed African Americans reported having talked to God $(p \leq .01)$, read the bible $(p=.02)$, and prayed to God alone $(p \leq .01)$ than the depressed Whites, whereas more depressed Whites reported having prayed for oneself with other nonfamily members such as pastor, hospital staff $(p=.04)$. No significant group differences were observed in the themes of belief in God's plan and healing power, attending churches, religious background and self-appraisal of faith.

\section{DISCUSSION}

Three main findings from this study shed light on a relationship between depression and spirituality in African American cancer patients. First, at the time of learning a cancer diagnosis, depressed African Americans questioned God "Why me?" and they were not significantly different 
Table 2. Thematic Difference by Race and Depression

\begin{tabular}{|c|c|c|c|c|c|}
\hline \multirow{2}{*}{ Themes } & \multirow{2}{*}{$\begin{array}{c}\text { Depressed African Americans } \\
\%(N)\end{array}$} & \multicolumn{2}{|c|}{ Non-Depressed African Americans } & \multicolumn{2}{|c|}{ Depressed Whites } \\
\hline & & $\%(N)$ & $p$-Value & $\%(N)$ & $p$-Value \\
\hline \multicolumn{6}{|l|}{ Religious Belief } \\
\hline Having a faith in God & $62 \%(21)$ & $74 \%(17)$ & 0.40 & $30 \%(5)$ & 0.04 \\
\hline Believed in God's healing power & $18 \%(6)$ & $13 \%(3)$ & 0.73 & 0 & 0.16 \\
\hline Believed in God's purposeful plan & $12 \%(4)$ & $26 \%(6)$ & 0.29 & $18 \%(3)$ & 0.67 \\
\hline Asked God "why me?" & $21 \%(7)$ & 0 & 0.03 & $12 \%(2)$ & 0.70 \\
\hline \multicolumn{6}{|l|}{ Religious Practice } \\
\hline Prayed by self & $41 \%(14)$ & $17 \%(4)$ & 0.08 & $6 \%(1)$ & 0.01 \\
\hline Prayed with others for oneself & $3 \%(1)$ & 0 & 1.00 & $24 \%(4)$ & 0.04 \\
\hline Talked to (conversed with) God & $32 \%(11)$ & $30 \%(7)$ & 1.00 & 0 & 0.01 \\
\hline Read bibles & $29 \%(10)$ & $22 \%(5)$ & 0.56 & 0 & 0.02 \\
\hline Attend church regularly & $29 \%(10)$ & $30 \%(7)$ & 1.00 & $24 \%(4)$ & 0.75 \\
\hline \multicolumn{6}{|l|}{ Religious Background } \\
\hline Grow up with strong faith & $15 \%(5)$ & $26 \%(6)$ & 0.32 & $6 \%(1)$ & 0.65 \\
\hline Spiritual but nonreligious & $6 \%(2)$ & $13 \%(3)$ & 0.38 & $12 \%(2)$ & 0.59 \\
\hline \multicolumn{6}{|l|}{ Appraisal of Faith } \\
\hline Faith helped get through cancer & $32 \%(11)$ & $57 \%(13)$ & 0.10 & $29 \%(5)$ & 1.00 \\
\hline Cancer strengthened faith in God & $3 \%(1)$ & $13 \%(3)$ & 0.29 & 0 & 1.00 \\
\hline
\end{tabular}

from the depressed Whites in this regard $(p=0.7)$, but the non-depressed African Americans did not report this experience $(p=.03)$. Secondly, as cancer treatment continued, significantly more depressed African Americans read the Bible $(p=.02)$ and talked to $\operatorname{God}(p=.01)$ than did the depressed Whites. Finally, more depressed African Americans prayed alone $(p \leq .01)$, while more depressed Whites prayed with other people (non-family members) $(p=.04)$.

The initial upset at getting a diagnosis of cancer and questioning God indicate an elevated emotional response to cancer as a life-threatening event. The experience of learning a cancer diagnosis appears to reshape a spiritual relationship with God in the depressed African American cancer patients and may explain the higher frequency of praying, conversing with God and reading the Bible among this group of patients. The fact that twice the number of depressed African Americans as depressed Whites reported having faith in God $(p=.04)$ supports this inference. Consistent with the literature $[3,4]$, the findings show that depressed African Americans are more reliant on God and their spirituality in the face of cancer.

The findings also suggest that perhaps questioning God and increasingly frequent praying or other religious activities (reading the Bible, talking to God) are not only a natural response to acute stress, but also a sign of mental stress as antecedents to depression. Therefore, it would be helpful to monitor prayer and identify a higher level of prayer that may indicate heightened stress and potential depression. This approach would be somewhat novel, and could help researchers and clinicians to unravel the intricacies in these two overlapping phenomena-spirituality and depression among African Americans.

There are several possible explanations regarding the differences between depressed African Americans and depressed Whites in their ways of praying. African Americans may view their relationship with God to be more private and confidential. In addition, many African Americans consider their conversations with God highly personal and free of any misunderstandings from professionals or family members. The opportunity of praying with someone else could be limited for African Americans. For example, fewer depressed African Americans than depressed Whites were married (29\% vs 59\%). Living alone may affect a person's willingness to open up to other people that are not part of the family. However, the non-depressed African Americans were not different from the depressed Whites in marital status (52\% vs 59\%) and, yet, they did not report praying with others. These findings, together, suggest that the relationship between praying and living condition (i.e., living alone) requires further investigation.

Further, stigma of cancer exists in the African American community. It was previously reported that $70 \%$ African American women were somewhat reluctant to discuss cancer with others [17] and social stigmas were high in these women [6]. Concerns about sharing diagnostic information and its potential impact on social relationship may prohibit African American cancer patients from sharing a prayer with others at a time when they need support and are experiencing symptoms of depression [18]. This hypothesis, although it requires further evidential support, alerts us to be mindful of the inclusion of African Americans in social activities such 
as prayer while being respectful of their privacy and personal choice. Further research is needed to determine when and how to embrace African Americans in prayers, and how to enhance the power of pray in their lives during this critical period.

\section{CONCLUSION}

Overall, the findings suggest an increasing need for praying in the depressed African American than depressed White cancer patients in the face of cancer. The implications are that African Americans without a strong faith could be at an increasing risk of depression. Religious and spiritual activities are sought to strengthen one's defense against depression. Because they are totally under the patient's control and hence particularly appealing to African Americans, these activities can be utilized to bring meanings to lives and facilitate healing. For example, listening and opening up to the prayers of other cancer patients including strangers may allow African American cancer patients to vent and heal. A second step could be to encourage them to share their spirituality with groups, but only when they are psychologically comfortable to take this step. Their spiritual relationship with God may also provide an impetus for selfassessment of the level of distress and seeking treatment. Future research on spirituality in African American cancer patients should pay attention to the interface of religious activities and beliefs, their implications for mental health, and healing. Further examination of how religious activities are heightened by and also alleviate stress will allow spiritual coping to emerge as an alternative way of assessing and treating depression for a group of African Americans.

The study has a small number of White cancer patients and this may have limited our chance of finding other group difference. The data were based on self-report and the findings may look different when a systematic assessment approach is applied. Given the limitation of our current knowledge of spirituality and healing in depressed African Americans, information gained from this explorative study enlightens clinicians and researchers about spirituality and its role in this group of patients who have endured and survived cancer.

\section{CONFLICT OF INTEREST}

The authors confirm that this article content has no conflicts of interest.

\section{ACKNOWLEDGEMENTS}

The study was supported by the National Institutes of Health/National Cancer Institute (R03 CA115191-01A2; PI:
Zhang). The Cleveland Department of Veterans Affairs Medical Center and other hospitals affiliated with the Case Western Reserve University provided support for patient access.

\section{REFERENCES}

[1] Lee MM, Lin SS, Wrensch MZR, Adler SR, Eisenberg D. Alternative therapies used by women with breast cancer in four ethnic populations. J Natl Cancer Inst 2000; 92: 42-7.

[2] Sheldrake P. A brief history of spirituality. Malden, MA: Blackwell Pub 2007.

[3] Lackey NR, Gates MF, Brown G. African American women's experiences with the initial discovery, diagnosis, and treatment of breast cancer. Oncol Nurs Forum 2001; 28(3): 519-27.

[4] Simon CE, Crowther M, Higgerson H. The stage-specific role of spirituality among African American Christian women throughout the breast cancer experience. Cultur Divers Ethnic Minor Psychol 2007; 13(1): 26-34.

[5] Bourjolly JN, Hirshmann KB. Similarities in coping strategies but differences in sources of support among African American women and white women coping with breast cancer. J Psychosoc Oncol 2001; 19: 17-38.

[6] Tate JD. The role of spirituality in the breast cancer experiences of African American women. J Holistic Nurs 2011; 29 (4): 249-55.

[7] Gibson LM, Hendricks CS. Integrative review of spirituality in African American breast cancer survivors. The Association of Black Nursing Faculty 2006; 17(2): 67-72.

[8] Maliski SL, Connor SE, Williams L, Litwin MS. Faith among lowincome, African American/black men treated for prostate cancer. Cancer Nurs 2010; 33(6): 470-8

[9] Levine EG, Yoo G, Aviv C, Ewing C, Au A. Ethnicity and spirituality in breast cancer survivors. J Cancer Surviv 2007; 1: 212-25.

[10] Gibson LMR, Parker V. Inner resources as predictors of psychological well-being in middle-income African American breast cancer survivors. Cancer Control 2003; 10: 52-9.

[11] Morgan PD, Tyler ID, Fogel J. Fatalism revisited. Semin Oncol Nurs 2008; 24(4): 237-45.

[12] Yawar A. Spirituality in medicine: What is to be done? J Royal Soc Med 2001; 94: 529-33.

[13] American Cancer Society. Cancer Facts \& Figures 2011. Atlanta, GA: American Cancer Society Inc. 2011.

[14] Tashakkori A, Teddlie C. Handbook of Mixed Methods in Social \& Behavioral Research. Thousand Oaks, London, New Delhi: Sage Publications 2003; pp. 365, 367, 461 .

[15] Sue S. In search of cultural competence in psychotherapy and counseling. Am Psychol 1998; 53(4): 440-48.

[16] Muhr T, Friese S. User's Manual for ATLAS.ti 5.0. $2^{\text {nd }}$ ed. Berlin, Germany: Scientific Software Development 2004.

[17] Ashing-Giwa K. Quality of life and psychosocial outcomes in longterm survivors of breast cancer: A focus on African-American women. J Psychosoc Oncol 1999; 17(3-4): 47-62.

[18] Hamilton JG, Moore CE, Powe BD, Agarwal M, Martin P. Perception of support among older African American cancer survivors. Oncol Nurs Forum 2010; 37 (4): 484-93. 